Article

\title{
Hydrogen Sensing Properties of Co-Doped ZnO Nanoparticles
}

\author{
Fatemeh Moosavi ${ }^{1}$, Mohammad Ebrahim Bahrololoom ${ }^{1}$, Ramin Kamjou ${ }^{2}$, Ali Mirzaei ${ }^{3}$, \\ Salvatore Gianluca Leonardi ${ }^{4}$ (D) and Giovanni Neri ${ }^{4, *}$ \\ 1 Department of Materials Science and Engineering, Shiraz University, Shiraz 71964-84334, Iran; \\ Fateme.moosavi68@gmail.com (F.M.); bahrolom@shirazu.ac.ir (M.E.B.) \\ 2 Young Researchers and Elite Club, Islamic Azad University, Shiraz Branch, Sadra city, Shiraz 74731-71987, \\ Iran; rkamjou@gmail.com \\ 3 Department of Materials Science and Engineering, Shiraz University of Technology, Shiraz 71557-13876, Iran; \\ alisonmirzaee@yahoo.com \\ 4 Department of Engineering, University of Messina, Contrada di Dio, I-98166 Messina, Italy; \\ Leonardis@unime.it \\ * Correspondence: gneri@unime.it
}

Received: 28 October 2018; Accepted: 3 December 2018; Published: 5 December 2018

check for updates

\begin{abstract}
In this study, the gas sensing properties of Co-doped $\mathrm{ZnO}$ nanoparticles (Co-ZnO NPs) synthesized via a simple sol-gel method are reported. The microstructure and morphology of the synthesized Co-ZnO NPs were characterized by X-ray diffraction (XRD) and transmission electron microscopy (TEM), respectively. Co-ZnO NPs were then used for developing a conductometric gas sensor for the detection, at mild temperature, of low concentration of hydrogen $\left(\mathrm{H}_{2}\right)$ in air. To evaluate the selectivity of the sensor, the sensing behavior toward some VOCs such as ethanol and acetone, which represent the most important interferents for breath hydrogen analysis, was also investigated in detail. Results reported demonstrated better selectivity toward hydrogen of the Co-ZnO NPs sensor when compared to pure $\mathrm{ZnO}$. The main factors contributing to this behavior, i.e., the transition from $n$-type behavior of pristine $\mathrm{ZnO}$ to $p$-type behavior upon Co-doping, the modification of oxygen vacancies and acid-base characteristics have been considered. Hence, this study highlights the importance of $\mathrm{Co}$ doping of $\mathrm{ZnO}$ to realize a high performance breath hydrogen sensor.
\end{abstract}

Keywords: Co-doped ZnO; nanoparticle; sol-gel; hydrogen; ethanol; gas sensor; sensing mechanism

\section{Introduction}

$\mathrm{ZnO}$ has been one of the most investigated material for gas sensing by using conductometric sensors, i.e., devices whose response is related to the resistance variation of the sensitive element upon exposure to target gases [1]. In the pristine form, $\mathrm{ZnO}$ is an $n$-type semiconducting metal oxide with a wide direct band gap $(\sim 3.3 \mathrm{eV})$, high exciton binding energy $(60 \mathrm{meV})$, excellent chemical and thermal stability, and a low price [2,3]. Nanosized ZnO due to fascinating properties imprinted by the small dimension is used in the transparent electrodes [4], solar cells [5], transducers [6], optoelectronic devices [7], UV sensors [8], and gas sensors [9,10]. Regarding gas sensing application, nanostructured $\mathrm{ZnO}$ materials have been reported for detection of both oxidative and reducing gases such as various VOCs [11-15], LPG [2], acetylene [16], $\mathrm{NO}_{2}$ [17], ammonia [18], and $\mathrm{H}_{2}$ [19] with good performance. $\mathrm{ZnO}$-based sensors are often preferred to other metal oxide-based conductive sensors to detect gaseous species due to their particular features such as high sensitivity, ease of fabrication, and very low cost [20].

$\mathrm{ZnO}$ has been largely investigated for $\mathrm{H}_{2}$ sensing [21-24]. Sensing properties toward this gas are particularly remarkable when $\mathrm{ZnO}$ is in a nanostructured form [25]. However, doping $\mathrm{ZnO}$ with 
noble metals such as $\mathrm{Pd}$ is a somewhat required additional step to obtain the desired high sensitivity for advanced applications. For example, Wang et al. [26] employed ZnO nanorods coated with Pd to detect $\mathrm{H}_{2}$ down to $10 \mathrm{ppm}$ with a relative response of $2.6 \%$ at $10 \mathrm{ppm}$ and a recovery time of less than $20 \mathrm{~s}$ at $25^{\circ} \mathrm{C}$.

On the other hand, noble metals are expensive. Therefore, we decided to focus our attention on developing high performance doped-ZnO sensors for hydrogen by using cheaper additives/modifiers. In this case, we report the research activity made to investigate the hydrogen sensing properties of Co-doped $\mathrm{ZnO}$ sensor. There are few studies reporting on the addition $\mathrm{Co}$ on $\mathrm{ZnO}$ and leading to the formation of $\mathrm{Co}_{3} \mathrm{O}_{4} / \mathrm{ZnO}$ heterojunctions with $p$-type behavior [27]. Co-doped $\mathrm{ZnO}$ nanocomposites show good sensing properties toward $\mathrm{H}_{2}$ monitoring at very low concentration, which is of utmost importance for detecting this gas in the human breath [28]. Hydrogen found in the breath of humans can be an indicator of some diseases like neonatal necrotizing enterocolitis, lactose intolerance, fructose malabsorption, and diabetic gastroparesis. Accordingly, high performance hydrogen sensors are of utmost importance and are highly demanding in the biomedical field.

However, one of the biggest drawbacks of metal oxide conductometric hydrogen sensors is the cross-sensitivity to other gases present in the breath, especially acetone $\left(\mathrm{C}_{3} \mathrm{H}_{6} \mathrm{O}\right)$ and ethanol $\left(\mathrm{C}_{2} \mathrm{H}_{5} \mathrm{OH}\right)$. These two volatile organic compounds (VOCs) are present in the breath of humans and their concentrations varies as a consequence of different factors. For instance, while the concentration of ethanol in the breath of healthy people is almost negligible, its concentration reach high levels for many hours after drinking alcoholic beverages in excess [29,30]. In addition, acetone is present in higher concentrations in the breath under particular circumstances [31]. People with cases of diabetes that are not well controlled and suffering of ketoacidosis show higher levels of breath acetone compared to healthy people.

In this study, we synthesized pristine and Co-doped ZnO NPs by a facile and low temperature sol-gel method and investigated their electrical and sensing characteristics towards the monitoring of low hydrogen concentration. In particular, we focused our attention on the role of Co dopant in modifying the sensing characteristics of pristine $\mathrm{ZnO}$ for $\mathrm{H}_{2}$ monitoring at low concentration and selectivity against ethanol.

\section{Materials and Methods}

\subsection{Synthesis of Co-Doped $\mathrm{ZnO}$}

In order to synthesize Co-doped $\mathrm{ZnO} N P s$, zinc acetate dihydrate $\left(\mathrm{Zn}\left(\mathrm{CH}_{3} \mathrm{COO}\right)_{2} \cdot 2 \mathrm{H}_{2} \mathrm{O}\right)$, cobalt acetate tetrahydrate $\left(\mathrm{Co}\left(\mathrm{CH}_{3} \mathrm{COO}\right)_{2} \cdot 4 \mathrm{H}_{2} \mathrm{O}\right)$, isopropanol $\left(\mathrm{CH}_{3} \mathrm{C}_{2} \mathrm{H}_{5} \mathrm{OH}\right)$, and monoethanolamine $\left(\mathrm{C}_{2} \mathrm{H}_{7} \mathrm{NO}\right)$ were used. All chemicals used in the experiment were of analytical grades. Doped $\mathrm{ZnO}$ NPs were synthesized by the following procedure. First, $0.917 \mathrm{~g}(0.005 \mathrm{~mol})\left(\mathrm{Zn}\left(\mathrm{CH}_{3} \mathrm{COO}\right)_{2} \cdot 2 \mathrm{H}_{2} \mathrm{O}\right)$ was dissolved in $10 \mathrm{~mL}$ isopropanol. Then $0.060 \mathrm{~g}(0.001 \mathrm{~mol})$ monoethanolamin was added to the $\mathrm{Zn}^{2+}$ solution as a stabilizer. Subsequently, $0.249 \mathrm{~g}(0.001 \mathrm{~mol})\left(\mathrm{Co}\left(\mathrm{CH}_{3} \mathrm{COO}\right)_{2} \cdot 4 \mathrm{H}_{2} \mathrm{O}\right)$ was added to the above solution and the obtained solution was stirred at $70{ }^{\circ} \mathrm{C}$ for $1 \mathrm{~h}$ to accelerate the hydrolysis reactions. The final solution was clear in color and homogeneous. After three weeks kept at room temperature, the solution was changed to a highly viscous gel. Lastly, the obtained gel was calcined at $400{ }^{\circ} \mathrm{C}$ for $1 \mathrm{~h}$ in a muffle furnace. For synthesis of pristine $\mathrm{ZnO}$ NPs, the procedure was the same. However, in this case, the cobalt precursor was not added to the prepared solution.

\subsection{Characterization}

Phase and crystallinity of synthesized powders were analyzed by X-ray diffraction. XRD data were collected by a Bruker D8 Advance Diffractometer (Bruker AXS, Karlsruhe, Germany) using the $\mathrm{CuK}_{\alpha 1}$ wavelength of $1.5405 \AA$. Morphological analysis was carried out by using transmission electron microscopy (TEM-Philips CM 200, Philips, Eindhoven, Netherlands). 


\subsection{Gas Sensing Measurements}

Gas sensors were fabricated as follows: first, synthesized nano-powders were mixed with distilled water and deposited on cleaned $\mathrm{Al}_{2} \mathrm{O}_{3}$ sensor substrates by a drop coating method. The size of the sensor substrate platform was $6 \mathrm{~mm} \times 3 \mathrm{~mm}$ and comprised a pair of interdigitated Pt electrodes on the front side and a resistive heater on its backside. The sensing area where the $\mathrm{ZnO}$ or Co-doped $\mathrm{ZnO}$ sensing material had to be deposited is $2 \mathrm{~mm} \times 2 \mathrm{~mm}$. Before sensing tests, the sensor was conditioned in air for $2 \mathrm{~h}$ at $300{ }^{\circ} \mathrm{C}$. Hydrogen sensing tests were performed by injecting pulses of the target gas from certified bottles and measuring the change in resistance. The sensors were tested at different temperatures under a synthetic dry air stream of $100 \mathrm{sccm}$ as carrier gas. By collecting the resistance data in the four-point mode, the gas response, $S$, was defined as $S=R_{0} / R$ (for pristine sensor) or $S$ $=R / R_{0}$ (for Co-doped gas sensor) where $R_{0}$ is the baseline resistance in air and $R$ is the electrical resistance of the sensor in the presence of hydrogen or other gases tested, respectively. The response time is defined as the time required for a sensor to reach $90 \%$ of its final value after introducing the gas pulse and the recovery time was defined as the time required for the sensor to reach $90 \%$ of its original baseline signal after returning to air flow.

\section{Results}

\subsection{Morphological and Microstructural Characterization}

The TEM micrograph of Co-doped $\mathrm{ZnO}$ sensor is shown in Figure 1. As can be seen, it consists of $\mathrm{ZnO}$ NPs with a hexagonal shape and with an approximate size of $25 \mathrm{~nm}$.

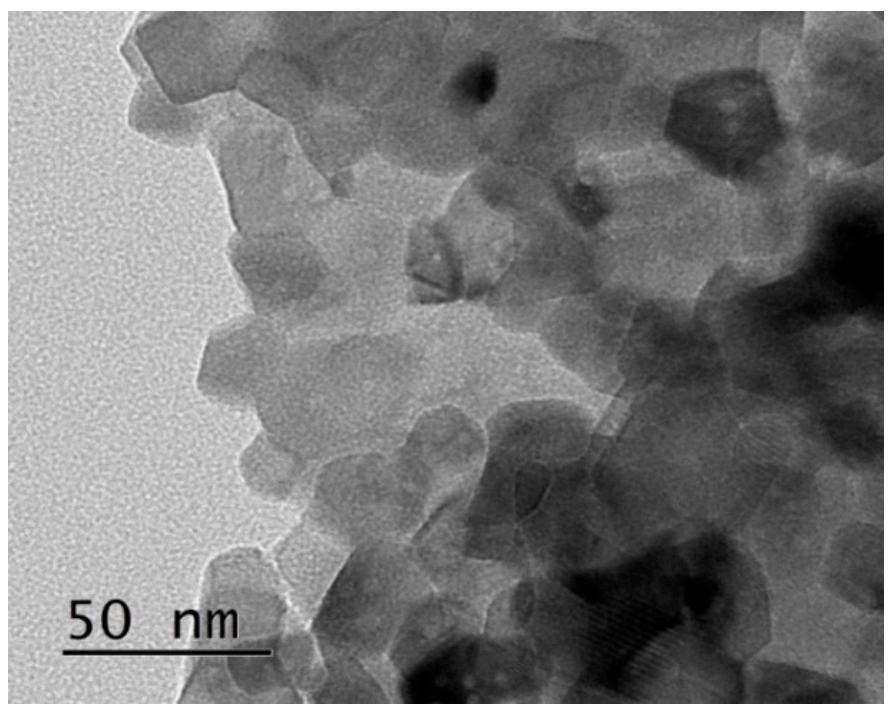

Figure 1. TEM micrograph of Co-doped ZnO NPs.

Figure 2 shows the XRD pattern of pristine $\mathrm{ZnO}$ and Co-doped $\mathrm{ZnO}$ NPs. The XRD pattern of pristine $\mathrm{ZnO}$ shows diffraction peaks related to the formation of $\mathrm{ZnO}$ with the hexagonal wurtzite structure while no other peaks due to the presence of impurities were observed. In the XRD pattern of Co-doped $\mathrm{ZnO} N P s$, peaks related to both crystalline $\mathrm{ZnO}$ and $\mathrm{Co}_{3} \mathrm{O}_{4}$ phases can be observed. The co-dopant can mainly be sorted into two categories: (i) in the crystal lattice substituting the original atom and (ii) forming other phases besides the original one [25]. From the XRD data reported in this study, it appears that $\mathrm{Co}_{3} \mathrm{O}_{4}$ has been formed as a separate phase. However, it cannot be excluded that a part of Co replaces $\mathrm{Zn}$ in the $\mathrm{ZnO}$ lattice. This could occur with little or without change of the $\mathrm{ZnO}$ wurtzite structure due to the small difference between the ionic radius of the $\mathrm{Zn}(0.740 \AA)$ and $\mathrm{Co}$ (0.745 ̊). 


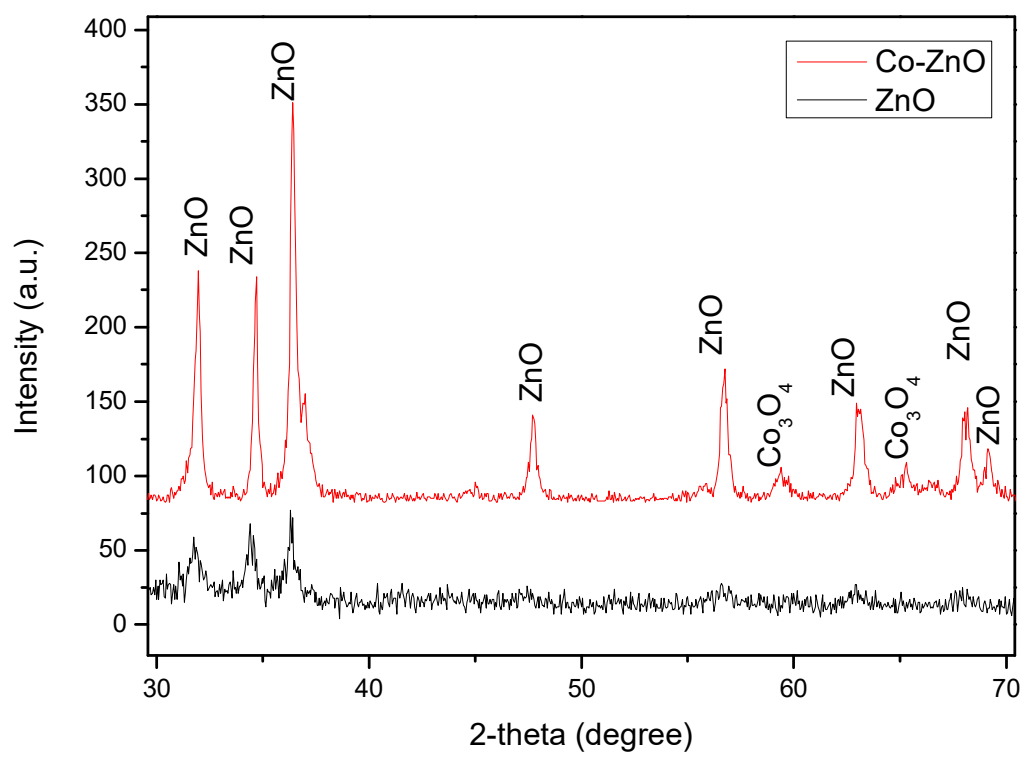

Figure 2. XRD patterns of pristine $\mathrm{ZnO}$ and Co-doped $\mathrm{ZnO}$ NPs.

\subsection{Sensing Tests}

First, the gas sensing properties of pristine $\mathrm{ZnO}$ and Co-doped $\mathrm{ZnO}$ sensors were compared. It is well known that the performances of the semiconductor gas sensors are greatly influenced by the working temperature because gas adsorption, reaction, and desorption are temperature-dependency phenomena [11]. Preliminary tests (not shown) indicated that the fabricated $\mathrm{ZnO}$ and Co-doped $\mathrm{ZnO}$ sensors shows best performances in the temperature range between $150{ }^{\circ} \mathrm{C}$ to $250{ }^{\circ} \mathrm{C}$.

Thus, to compare the sensing performances of these sensors, the operating temperature was set at $200{ }^{\circ} \mathrm{C}$. Figure 3 a reports the transient response to $50 \mathrm{ppm}$ of $\mathrm{H}_{2}$ on $\mathrm{ZnO}$ sensor. In the presence of hydrogen, the resistance show a fast decrease. The response is very high $(S=18)$. However, one limitation of this $\mathrm{ZnO}$ sensor is the cross-sensitivity of other gases present in the breath and in specifically acetone and ethanol. This is well evident in Figure $3 b$ where the response of the pristine $\mathrm{ZnO}$ sensor to hydrogen is compared with the higher response observed when exposed to the previously mentioned VOCs.

The sensing behavior of Co-doped $\mathrm{ZnO}$ sensor in the same conditions have been evaluated and reported in Figure $4 \mathrm{a}, \mathrm{b}$. Using this comparison, some findings appear to be very clear. First, a pristine $\mathrm{ZnO}$ gas sensor shows $n$-type semiconducting behavior while the Co-doped gas sensor shows a clear $p$-type behavior, which indicates a change of the semiconducting behavior upon Co-doping [32]. Second, even if the pristine $\mathrm{ZnO}$ sensor is more sensitive than the Co-doped $\mathrm{ZnO}$ gas sensor, its selectivity to hydrogen is poorer. Furthermore, the Co-doped $\mathrm{ZnO}$ sensor shows a faster dynamics response compared to a pristine $\mathrm{ZnO}$ sensor. The response and recovery time of the Co-doped $\mathrm{ZnO}$ based sensor are $20 \mathrm{~s}$ and $150 \mathrm{~s}$, respectively. The recovery time is much shorter than that observed with the pristine $\mathrm{ZnO}$ sensor (>200 s). This suggests that the desorption stage represents the rate-determining step for the overall process.

Figure $5 \mathrm{a}, \mathrm{b}$ show dynamic resistance curves of pristine $\mathrm{ZnO}$ and Co-doped $\mathrm{ZnO}$ NPs, respectively, registered at $200{ }^{\circ} \mathrm{C}$ toward a pulse of $10 \mathrm{ppm}$ ethanol. As previously mentioned, the Co-doped $\mathrm{ZnO}$ sensor shows a lower response to ethanol in comparison to the pristine $\mathrm{ZnO}$ sensor, which is advantageous because it means that this gaseous species present low interference for the determination of breath hydrogen. The response time is faster for the Co-doped ZnO sensor (less than 50 s) when compared to the pristine $\mathrm{ZnO}$-based sensor (around $200 \mathrm{~s}$ ). Furthermore, a longer recovery time has been recorded for the pristine $\mathrm{ZnO}$-based sensor (around $750 \mathrm{~s}$ ) when compared to the Co-doped one (less than 200 s). 


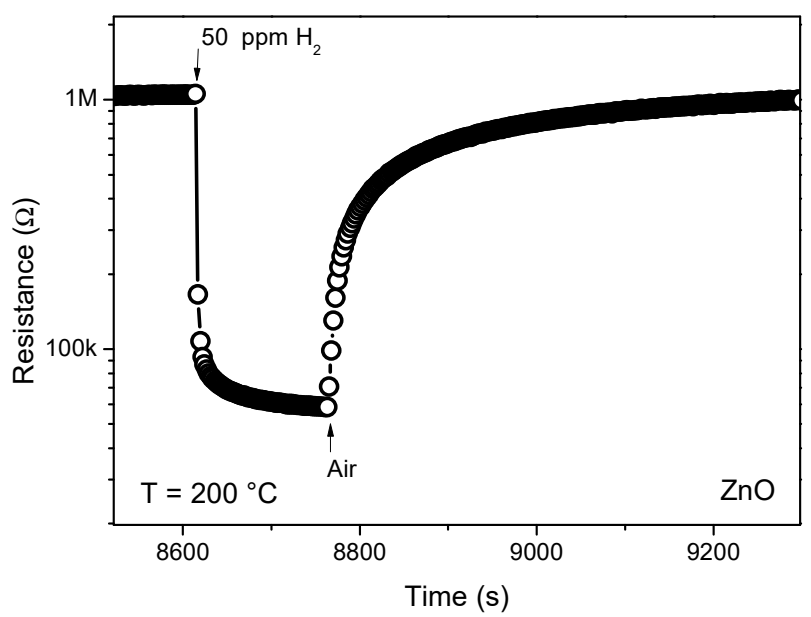

(a)

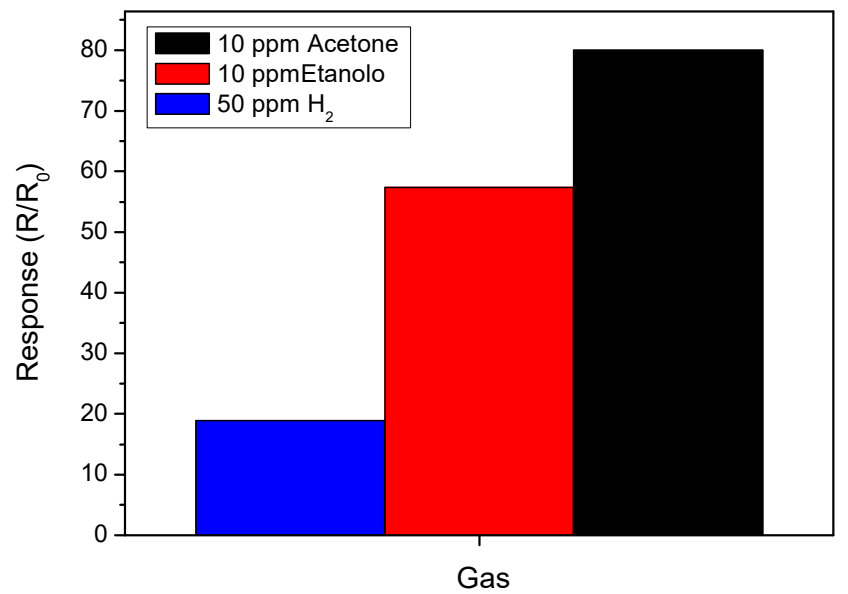

(b)

Figure 3. (a) Transient response to $50 \mathrm{ppm}$ of $\mathrm{H}_{2}$ of the $\mathrm{ZnO}$ sensor. (b) Comparison of the response of the $\mathrm{ZnO}$ sensor to $\mathrm{H}_{2}$, acetone, and ethanol.

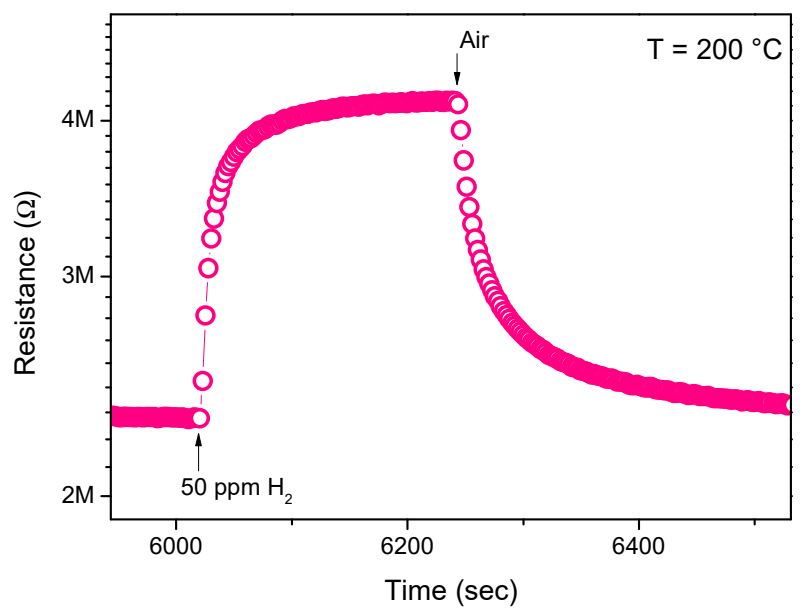

(a)

Figure 4. Cont. 


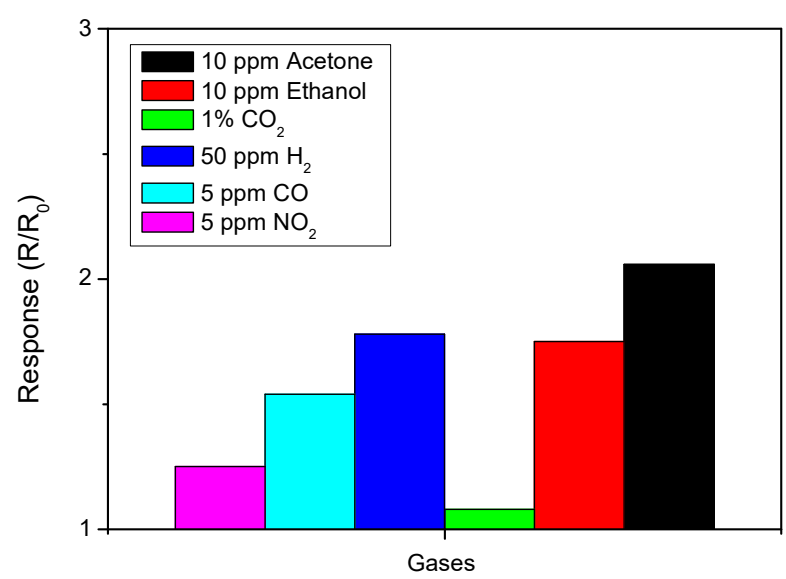

(b)

Figure 4. (a) Transient response to $50 \mathrm{ppm}$ of $\mathrm{H}_{2}$ of $\mathrm{Co}$-doped $\mathrm{ZnO}$ sensor. (b) Comparison of the response of Co-doped $\mathrm{ZnO}$ sensor to $\mathrm{H}_{2}$, acetone, ethanol, and other environmental interferent gases.

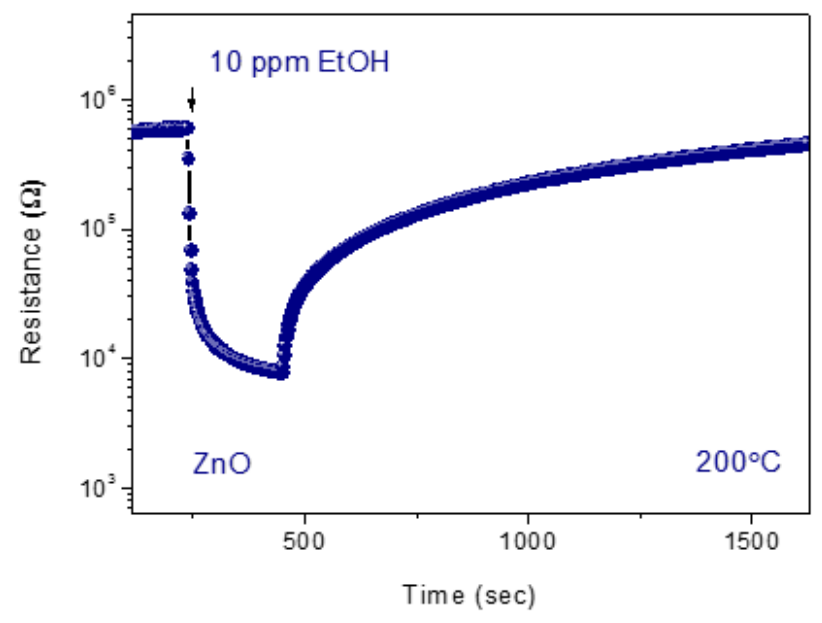

(a)

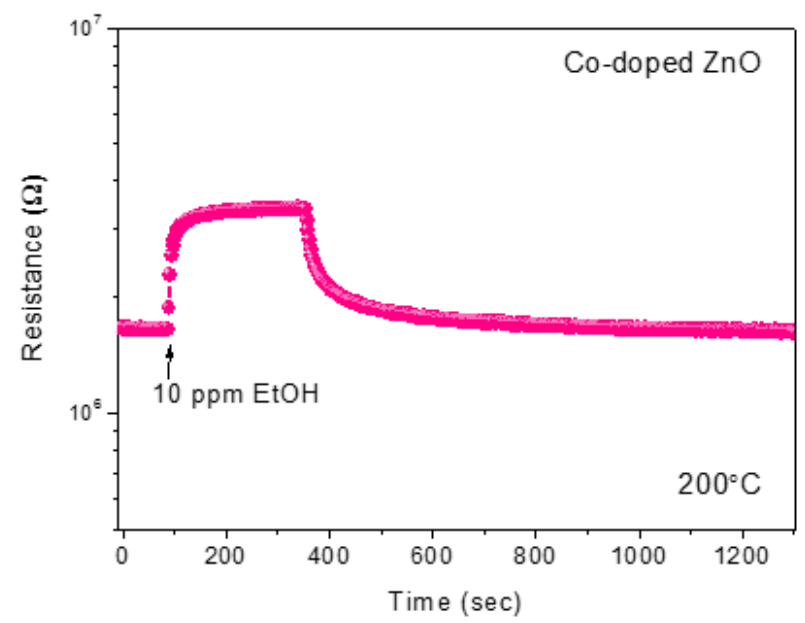

(b)

Figure 5. Response to $10 \mathrm{ppm}$ of ethanol gas at different temperatures for (a) $\mathrm{ZnO}$ and (b) a Co-doped $\mathrm{ZnO}$ gas sensor. 
A possible reason behind the decrease of response of the Co-doped sensor toward ethanol is the decrease of oxygen vacancies in $\mathrm{ZnO}$ due to Co-doping. In fact, $n$-type behavior in pristine $\mathrm{ZnO}$ suggests the presence of oxygen vacancies, which can be considered the adsorption sites for effective adsorption of ethanol. In the Co-doped $\mathrm{ZnO}$ gas sensor, the amount of oxygen vacancies significantly decreases, according to the $p$-type behavior and leads to the observed decrease of the sensor's response.

An acid-base change related to the introduction of the $\mathrm{Co}_{3} \mathrm{O}_{4}$ phase should be considered in this case. Acid-base characteristics of the sensing material are well known for addressing the sensing performances in metal oxide semiconductor gas sensors. In the framework of this hypothesis, the high sensitivity to ethanol found in pristine $\mathrm{ZnO}$ could be related to a large number of electrons involved in the pathway of total oxidation of ethanol (see Equation (3) below). This is a process favored on basic sites, which are known to be relatively abundant on the $\mathrm{ZnO}$ surface.

$$
\begin{gathered}
\mathrm{C}_{2} \mathrm{H}_{5} \mathrm{OH}_{(\text {ads })}+\mathrm{O}_{(\text {ads })}^{-} \rightarrow \mathrm{CH}_{3} \mathrm{CHO}_{(\text {ads })}+\mathrm{H}_{2} \mathrm{O}+\overline{\mathrm{e}} \\
\mathrm{CH}_{3} \mathrm{CHO}_{(\text {ads })}+5 \mathrm{O}_{(\text {ads })}^{-} \rightarrow 2 \mathrm{CO}_{2}+2 \mathrm{H}_{2} \mathrm{O}+5 \overline{\mathrm{e}} \\
\mathrm{CH}_{3} \mathrm{CHO}_{(\text {ads })}+6 \mathrm{O}_{(\text {ads })}^{2-} \rightarrow 2 \mathrm{CO}_{2}+3 \mathrm{H}_{2} \mathrm{O}+12 \overline{\mathrm{e}}
\end{gathered}
$$

In the presence of $\mathrm{Co}$, the response to ethanol is lower. This can be attributed to the higher surface acidity of the Co-doped $\mathrm{ZnO}$, which favors alternative pathways, e.g., through Equation (1), involving a strongly reduced number of electrons.

\subsection{Hydrogen Sensor Performances}

In view of the above findings, we decided to investigate the performances of the Co-doped $\mathrm{ZnO}$ gas sensor for hydrogen sensing at a low concentration. When the sensor is in an $\mathrm{H}_{2}$ atmosphere, hydrogen molecules react with adsorbed oxygen ions on the surface of the gas sensor, according to the following equation [33].

$$
\mathrm{H}_{2}+\mathrm{O}_{(\text {ads })}^{-} \rightarrow \mathrm{H}_{2} \mathrm{O}+\overline{\mathrm{e}}
$$

The released electrons will cause modulation of electrical resistance in the gas sensor and a signal will appear, which relies on the balance between the adsorption and desorption rate of $\mathrm{H}_{2}$ and surface reactivity with adsorbed oxygen species [1]. When the $n$-type $\mathrm{ZnO}$ sensor is in the air, oxygen molecules adsorb onto the sensing layer surface and, depending on the temperature, will be converted to oxygen ions (e.g., $\mathrm{O}_{2}^{-}, \mathrm{O}^{-}$or $\mathrm{O}_{2}$ ) by extraction of free electrons from the conductance band of $\mathrm{ZnO}$. Adsorbed oxygens ions will generate a region free of electrons, which is known as the electron depletion layer, EDL (see Scheme 1a). In hydrogen, these molecules will be chemisorbed on the surfaces of ZnO NPs. By a subsequent reaction between the hydrogen molecules and the adsorbed oxygen species, the trapped electrons are released back to the $\mathrm{ZnO} \mathrm{NPs}$ and $\mathrm{H}_{2} \mathrm{O}$ vapor is released. Accordingly, the thickness of EDL will decrease (Scheme 1b) and the resistance of the sensor decreases.

In the case of cobalt doped $\mathrm{ZnO}$ gas sensors, the $p$-type semiconducting behavior was observed. As shown in Scheme 1c, after exposure to air, oxygen molecules can be adsorbed on the surface of the sensor and a hole accumulation layer (HAL) will be formed on the surface of the sensor. Upon exposure to hydrogen vapor, electrons come back to the surface of the sensor, which results in a decrease of width of HAL and an increase of the sensor's resistance (Scheme 1d). A lower response of the Co-doped $\mathrm{ZnO}$ sensor relative to the pristine $\mathrm{ZnO}$ gas sensor can be attributed to the intrinsic lower response of the $p$-type semiconductor metal oxides relative to that of $n$-type counterparts [34].

Preliminary, it was found that the optimum operating temperature determined by exposure to $50 \mathrm{ppm} \mathrm{H}_{2}$ at different operating temperatures $\left(100-375{ }^{\circ} \mathrm{C}\right)$ is $150{ }^{\circ} \mathrm{C}$, which is lower than the temperature observed in a pristine $\mathrm{ZnO}$ sensor. In Figure $6 \mathrm{a}$, one can observe that the response trend increases with a rising operating temperature. It reaches its maximum at $150{ }^{\circ} \mathrm{C}$ and then decreases gradually. 
EDL

(a)

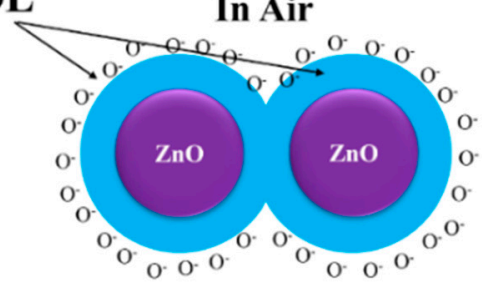

HAL

(c)

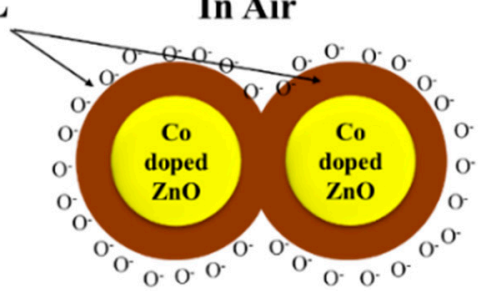

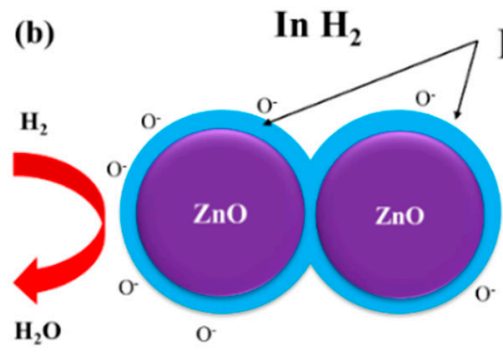

EDL

(d)

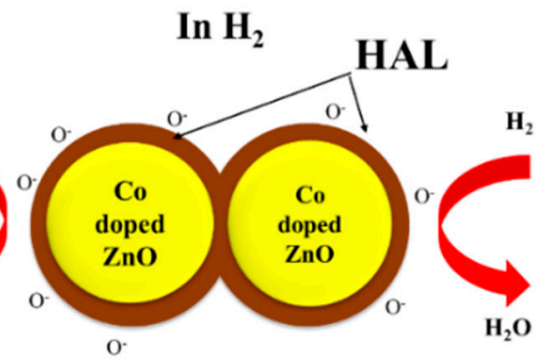

Scheme 1. Schematization of the $\mathrm{H}_{2}$ sensing mechanism in pristine and Co-doped $\mathrm{ZnO}$ gas sensors.

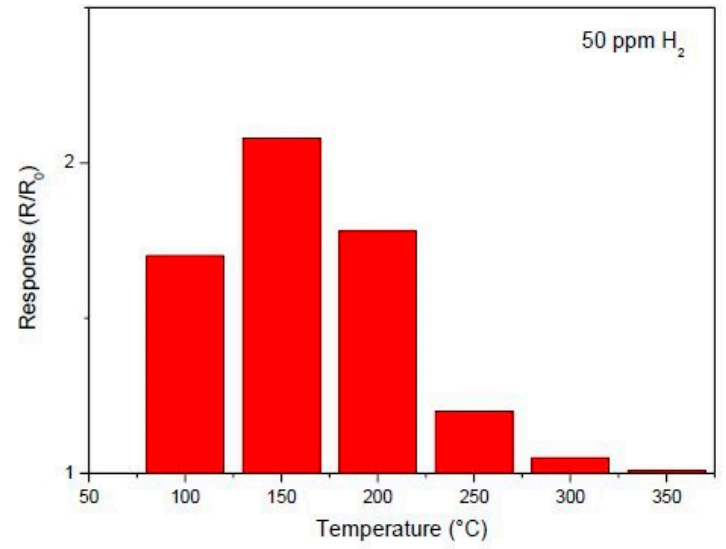

(a)

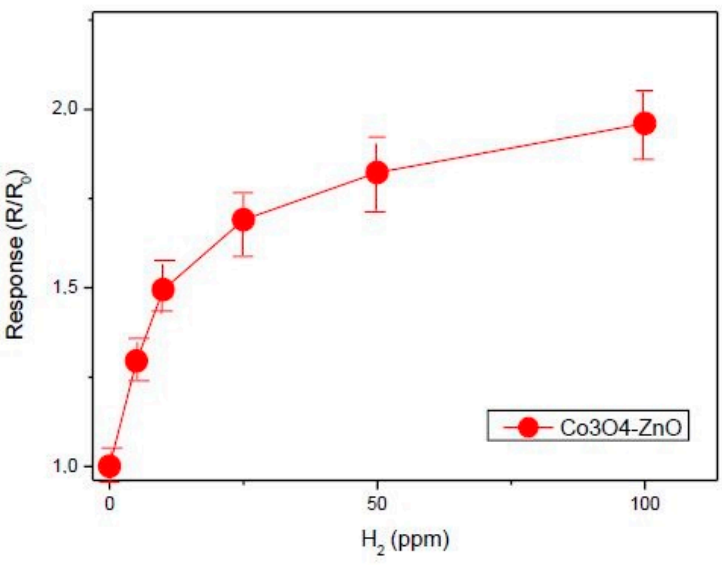

(c)

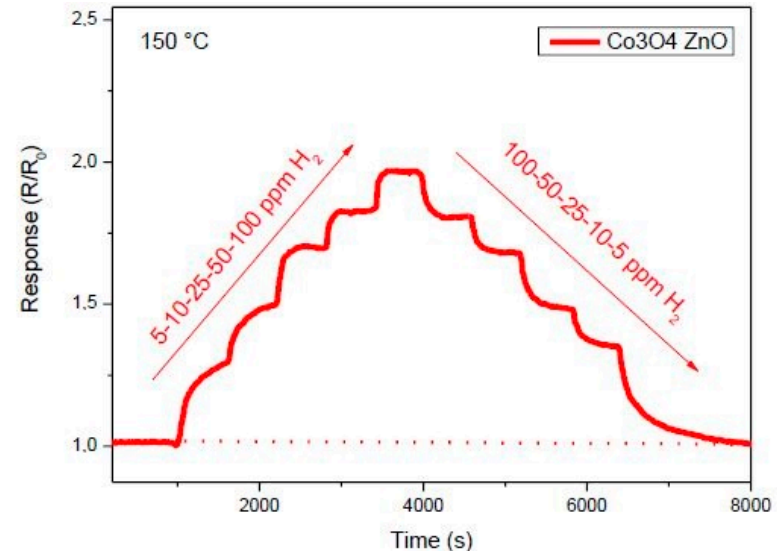

(b)

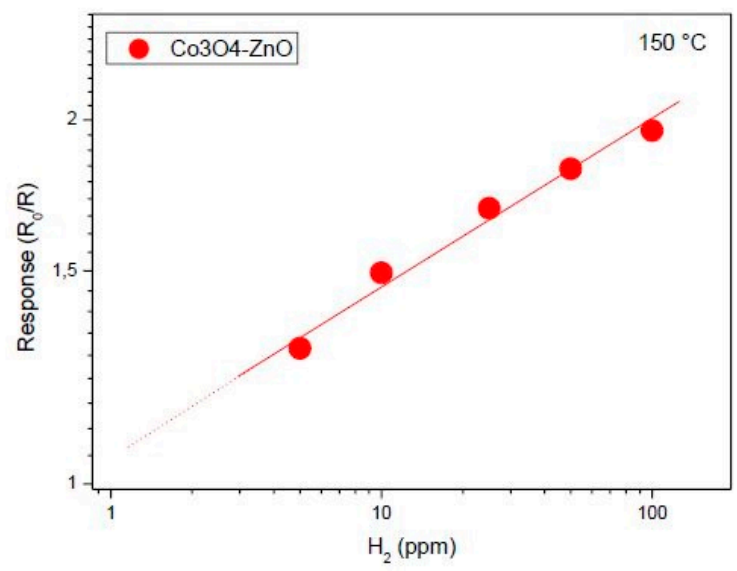

(d)

Figure 6. (a) Response vs. $\mathrm{H}_{2}$ concentration of the Co-doped $\mathrm{ZnO}$ sensor recorded at different temperatures. (b) Response to increasing and decreasing $\mathrm{H}_{2}$ concentration values at the temperature of $150{ }^{\circ} \mathrm{C}$. (c) Calibration curve in a linear scale. (d) Calibration curve in a log-log scale.

Afterward, responses of the sensor to low concentrations of $\mathrm{H}_{2}$ were investigated at the optimum operating temperature of $150{ }^{\circ} \mathrm{C}$. The sensor has been exposed to 5, 10, 25, 50, and $100 \mathrm{ppm}$ of $\mathrm{H}_{2}$. 
The exposing steps were repeated in the reverse order to verify the presence of "hysteresis" effects and the repeatability of the responses. Figure $6 \mathrm{~b}$ depicted the results obtained, highlighting that little or no hysteresis effects are retained. The response values obtained for increasing $\mathrm{H}_{2}$ concentrations are almost the same ones obtained when the $\mathrm{H}_{2}$ concentrations decrease, which suggests that the gas sensing process is reproducible and the device has a good repeatability.

The calibration curve in linear scale is shown in Figure 6c. The response curve increases rapidly with the increase of the $\mathrm{H}_{2}$ concentration below 25 ppm. However, the response growth becomes slower when the $\mathrm{H}_{2}$ concentration is above that value, which indicates that the sensor exhibits excellent sensing performance for a low concentration of $\mathrm{H}_{2}$. For $\mathrm{H}_{2}$ concentrations higher than 25 ppm, the current reaches saturation during the gas exposure. The log-log scale (see Figure $6 \mathrm{~d}$ ) allows us to appreciate that the limit of detection (LOD) for hydrogen of the Co-doped $\mathrm{ZnO}$ sensor is effectively very low at around $1 \mathrm{ppm}$.

\section{Conclusions}

In summary, pristine and Co-doped ZnO NPs were synthesized via the sol-gel method for electrical and gas sensing studies. The synthesized NPs were characterized by XRD and TEM. Electrical resistance measurements showed that the pristine $\mathrm{ZnO}$ sensor displayed a high response to hydrogen at a low concentration in air but with poor selectivity. Co-doping in $\mathrm{ZnO}$ reduced the response to hydrogen. However, we noted that the selectivity increased. This effect has been attributed to the changes of some chemical and physical parameters such as the acid-base characteristics, the $p$-type behavior, and the decrease of oxygen vacancies occurring in the Co-doped $\mathrm{ZnO}$ sensing layer. These peculiar characteristics were allowed to realize a high performance breath hydrogen sensor based on the synthesized $\mathrm{Co}-\mathrm{ZnO}$ nanocomposite, which displays a limit of detection at around 1 ppm and good selectivity for $\mathrm{H}_{2}$ in human breath.

Author Contributions: M.E.B. and G.N. conceived the project and defined experimental protocol. F.M., R.K. and S.G.L. carried out experiments. G.N. and A.M. completed the draft of manuscript.

Funding: This research received no external funding.

Acknowledgments: Authors are grateful for the partial support from the Iran Nanotechnology Initiative Council. Conflicts of Interest: The authors declare no conflicts of interest.

\section{References}

1. Neri, G. First fifty years of chemoresistive gas sensors. Chemosensors 2015, 3, 1-20. [CrossRef]

2. Dhawale, D.S.; Lokhande, C.D. Chemical route to synthesis of mesoporous $\mathrm{ZnO}$ thin films and their liquefied petroleum gas sensor performance. J. Alloys. Compd. 2011, 509, 10092-10097. [CrossRef]

3. Qi, Q.; Zeng, T.; Zeng, Y.; Yang, H. Humidity sensing properties of KCl-doped $\mathrm{Cu}-\mathrm{Zn} / \mathrm{CuO}-\mathrm{ZnO}$ nanoparticles. Sens. Actuators B Chem. 2009, 137, 21-26. [CrossRef]

4. Lee, J.H.; Ko, K.H.; Park, B.O. Electrical and optical properties of ZnO transparent conducting films by the sol-gel method. J. Cryst. Growth 2003, 247, 119. [CrossRef]

5. Olson, D.C.; Piris, J.; Collins, R.T.; Shaheen, S.E.; Ginley, D.S. Hybrid photovoltaic devices of polymer and ZnO nanofiber composites. Thin Solid Films 2006, 496, 26. [CrossRef]

6. Powell, D.A.; Kalantar-zade, K.; Wlodarski, W. Numerical calculation of SAW sensitivity: Application to $\mathrm{ZnO} / \mathrm{LiTaO}_{3}$ transducers. Sens. Actuators A Phys. 2004, 115, 456-461. [CrossRef]

7. Hu, Z.J.Y.; Xu, C.; Mei, T.; Guo, J.; White, T. Monodisperse ZnO nanodots: Synthesis, charaterization, and optoelectronic properties. J. Phys. Chem. C 2007, 111, 9757-9760. [CrossRef]

8. Chen, Y.L.H.; Xie, C.; Wu, J.; Zeng, D.; Liao, Y. A comparative study on UV light activated porous $\mathrm{TiO}_{2}$ and $\mathrm{ZnO}$ film sensors for gas sensing at room temperature. Ceram. Int. 2012, 38, 503-509. [CrossRef]

9. Mirzaei, A.; Park, S.; Kheel, H.; Sun, G.-J.; Lee, S.; Lee, C. ZnO-capped nanorod gas sensors. Ceram. Int. 2016, 42, 6187-6197. [CrossRef] 
10. Kwon, Y.J.; Kang, S.Y.; Mirzaei, A.; Choi, M.S.; Bang, J.H.; Kim, S.S.; Kim, H.W. Enhancement of gas sensing properties by the functionalization of $\mathrm{ZnO}$-branched $\mathrm{SnO}_{2}$ nanowires with $\mathrm{Cr}_{2} \mathrm{O}_{3}$ nanoparticles. Sens. Actuators B Chem. 2017, 249, 656-666. [CrossRef]

11. Mirzaei, A.; Leonardi, S.G.; Neri, G. Detection of hazardous volatile organic compounds (VOCs) by metal oxide nanostructures-based gas sensors: A review. Ceram. Int. 2016, 42, 15119-15141. [CrossRef]

12. Mirzaei, A.; Kim, J.-H.; Kim, H.W.; Kim, S.S. How shell thickness can affect the gas sensing properties of nanostructured materials: Survey of literature. Sens. Actuators B Chem. 2018, 258, 270-294. [CrossRef]

13. Leonardi, S.G. Two-dimensional zinc oxide nanostructures for gas sensor applications. Chemosensors 2017, 5, 17. [CrossRef]

14. Chu, X.; Chen, T.; Zhang, W.; Zheng, B.; Shui, H. Investigation on formaldehyde gas sensor with ZnO thick film prepared through microwave heating method. Sens. Actuators B Chem. 2009, 142, 49-54. [CrossRef]

15. Zeng, Y.; Zhang, T.; Yuan, M.; Kang, M.; Lu, G.; Wang, R.; Fan, H.; He, Y.; Yang, H. Growth and selective acetone detection based on $\mathrm{ZnO}$ nanorod arrays. Sens. Actuators B Chem. 2009, 143, 93-98. [CrossRef]

16. Dong, L.F.; Cui, Z.L.; Zhang, Z.K. Gas sensing properties of nano-ZnO prepared by arc plasma method. Nanostruct. Mater. 1997, 8, 815-823. [CrossRef]

17. Oh, E.; Choi, H.Y.; Jung, S.H.; Cho, S.; Kim, J.C.; Lee, K.H.; Kang, S.W.; Kim, J.; Yund, J.Y.; Jeong, S.H. High-performance $\mathrm{NO}_{2}$ gas sensor based on $\mathrm{ZnO}$ nanorod grown by ultrasonic irradiation. Sens. Actuators $B$ Chem. 2009, 141, 239-243. [CrossRef]

18. Wang, X.; Zhang, J.; Zhu, Z.; Zhu, J. Effect of $\mathrm{Pd}^{2+}$ doping on ZnO nanotetrapods ammonia sensor. Colloids Surf. A 2006, 276, 59-64. [CrossRef]

19. Aygün, S.; Cann, D. Hydrogen sensitivity of doped $\mathrm{CuO} / \mathrm{ZnO}$ heterocontact sensors. Sens. Actuators B Chem. 2005, 106, 837-842.

20. Wei, A.; Pan, L.; Huang, W. Recent Progress in the ZnO Nanostructure-Based Sensors. Mater. Sci. Eng. B 2011, 176, 1409-1421. [CrossRef]

21. Rout, C.S.; Raju, A.R.; Govindaraj, A.; Rao, C.N.R. Hydrogen sensors based on ZnO nanoparticles. Solid State Commun. 2006, 138, 136-138. [CrossRef]

22. Hoppe, M.; Lupan, O.; Postica, V.; Wolff, N.; Duppel, V.; Kienle, L.; Tiginyanu, I.; Adelung, R. $\mathrm{ZnAl}_{2} \mathrm{O}_{4}$-Functionalized zinc oxide microstructures for highly selective hydrogen gas sensing applications. Phys. Stat. Solidi 2018, 215, 1700772.

23. Sett, D.; Basak, D. Highly enhanced $\mathrm{H}_{2}$ gas sensing characteristics of $\mathrm{Co}$ : $\mathrm{ZnO}$ nanorods and its mechanism. Sens. Actuators B Chem. 2018, 243, 475-483. [CrossRef]

24. Reddy, P.; Reddy, K.S.; Reddy, B.; Manasa, M.V.; Devi, G.S.; Rao, G.N. Gas Sensing Characteristics of ZnO: $\mathrm{Nb}_{2} \mathrm{O}_{5}$ nanocomposite towards hydrogen gas. J. Adv. Phys. 2017, 6, 418-421. [CrossRef]

25. Jaaniso, R.; Kiang Tan, O. Semiconductor Gas Sensors; Woodhead Publishing Group: Sawston, UK, 2013.

26. Wang, H.T.; Kang, B.S.; Ren, F.; Tien, L.C.; Sadik, P.W.; Norton, D.P.; Pearton, S.J. Hydrogen-selective sensing at room temperature with $\mathrm{ZnO}$ nanorods. J. Appl. Phys. Lett. 2005, 86, 243503. [CrossRef]

27. Bekermann, D.; Gasparotto, A.; Barreca, D.; Maccato, C.; Comini, E.; Sada, C.; Sberveglieri, G.; Devi, A.; Fischer, R.A. $\mathrm{Co}_{3} \mathrm{O}_{4} / \mathrm{ZnO}$ nanocomposites: From plasma synthesis to gas sensing applications. ACS Appl. Mater. Interfaces 2012, 4, 928-934. [CrossRef]

28. Shin, W.; Goto, T.; Nagai, D.; Itoh, T.; Tsuruta, A.; Akamatsu, T.; Sato, K. Thermoelectric array sensors with selective combustion catalysts for breath gas monitoring. Sensors 2018, 18, 1579. [CrossRef]

29. Mirzaei, A.; Janghorban, K.; Hashemi, B.; Bonyani, M.; Leonardi, S.G.; Neri, G. Highly stable and selective ethanol sensor based on $\alpha-\mathrm{Fe}_{2} \mathrm{O}_{3}$ nanoparticles prepared by Pechini sol-gel method. Ceram. Int. 2016, 42, 6136-6144. [CrossRef]

30. Anderson, P.; Baumberg, B. Alcohol in Europe, A Public Health Perspective; A Report for the European Commission; European Commission: Brussels, Belgium, 2006.

31. Karmaoui, M.; Leonardi, S.G.; Latino, M.; Tobaldi, D.M.; Donato, N.; Pullar, R.C.; Neri, G. Pt-decorated $\operatorname{In}_{2} \mathrm{O}_{3}$ nanoparticles and their ability as a highly sensitive $(<10 \mathrm{ppb})$ acetone sensor for biomedical applications. Sens. Actuators B Chem. 2016, 230, 697-705. [CrossRef]

32. Ghosh, A.; Bannerjee, R.; Basu Majumder, S. Selective hydrogen sensing by cobalt doped ZnO thin films: A study on carrier reversal conductivity. In Proceedings of the IEEE Sensors, Busan, South Korea, 1-4 November 2015. 
33. Falsafi, F.; Hashemi, B.; Mirzaei, A.; Fazio, E.; Neri, F.; Donato, N.; Leonardi, S.G.; Neri, G. Sm-doped cobalt ferrite nanoparticles: A novel sensing material for conductometric hydrogen leak sensor. Ceram. Int. 2017, 43, 1029-1037. [CrossRef]

34. Kim, J.-H.; Lee, J.-H.; Mirzaei, A.; Kim, H.W.; Kim, S.S. Optimization and gas sensing mechanism of n- $\mathrm{SnO}_{2}-\mathrm{p}-\mathrm{Co}_{3} \mathrm{O}_{4}$ composite nanofibers. Sens. Actuators B Chem. 2017, 248, 500-511. [CrossRef] 